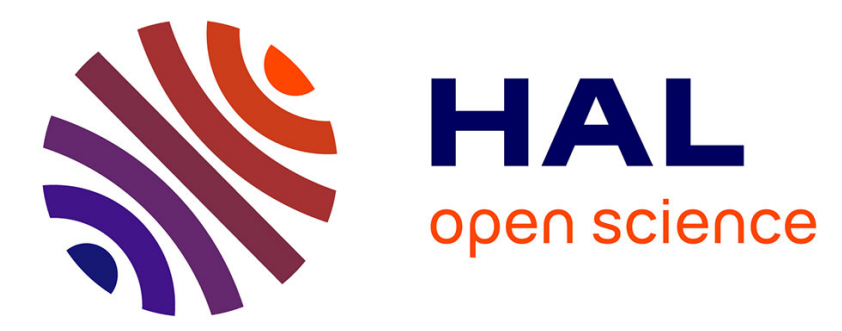

\title{
Hepatic Steatosis, Body Mass Index and long term outcome in patients undergoing hepatectomy for colorectal liver metastases
}

\author{
S. Pathak, J.M.F. Tang, M. Terlizzo, G.J. Poston
}

\section{- To cite this version:}

S. Pathak, J.M.F. Tang, M. Terlizzo, G.J. Poston. Hepatic Steatosis, Body Mass Index and long term outcome in patients undergoing hepatectomy for colorectal liver metastases. EJSO - European Journal of Surgical Oncology, 2010, 36 (1), pp.52. 10.1016/j.ejso.2009.09.004 • hal-00556322

\section{HAL Id: hal-00556322 \\ https://hal.science/hal-00556322}

Submitted on 16 Jan 2011

HAL is a multi-disciplinary open access archive for the deposit and dissemination of scientific research documents, whether they are published or not. The documents may come from teaching and research institutions in France or abroad, or from public or private research centers.
L'archive ouverte pluridisciplinaire HAL, est destinée au dépôt et à la diffusion de documents scientifiques de niveau recherche, publiés ou non, émanant des établissements d'enseignement et de recherche français ou étrangers, des laboratoires publics ou privés. 


\section{Accepted Manuscript}

Title: Hepatic Steatosis, Body Mass Index and long term outcome in patients undergoing hepatectomy for colorectal liver metastases

Authors: S. Pathak, J.M.F. Tang, M. Terlizzo, G.J. Poston

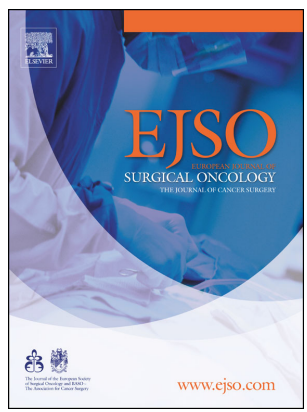

PII:

S0748-7983(09)00465-X

DOI:

10.1016/j.ejso.2009.09.004

Reference: YEJSO 2890

To appear in: European Journal of Surgical Oncology

Received Date: 8 April 2009

Revised Date: 6 September 2009

Accepted Date: 10 September 2009

Please cite this article as: Pathak S, Tang JMF, Terlizzo M, Poston GJ. Hepatic Steatosis, Body Mass Index and long term outcome in patients undergoing hepatectomy for colorectal liver metastases,

European Journal of Surgical Oncology (2009), doi: 10.1016/j.ejso.2009.09.004

This is a PDF file of an unedited manuscript that has been accepted for publication. As a service to our customers we are providing this early version of the manuscript. The manuscript will undergo copyediting, typesetting, and review of the resulting proof before it is published in its final form. Please note that during the production process errors may be discovered which could affect the content, and all legal disclaimers that apply to the journal pertain. 


\section{Title Page}

Conflicts Statement

\section{Authors:}

$\underline{\text { S. Pathak, Department of General Surgery, University Hospital Aintree }}$ J.M.F. Tang, University of Liverpool (medical student)

M. Terlizzo, Department of Pathology, University Hospital Aintree G.J Poston, Department of General Surgery, University Hospital Aintree

Work to be attributed to: Department of General Surgery, University Hospital Aintree

Author for correspondence: Mr S Pathak, Flat 173, 6 Royal Quay, Kings Dock, Liverpool, L3 4EX. Telephone no. : 00447779 607659. E Mail:

samirpathak@doctors.net.uk

\section{Conflict of Interests: Nil}

Funding: Nil

Guarantor: Mr Graeme Poston, Consultant Hepatobiliary Surgeon, University Hospital Aintree

Acknowledgements: Nil 


\section{Abstract}

Background: Hepatic Steatosis (HS) is as an independent risk factor for morbidity and mortality post-hepatectomy. Recent studies report significant correlation between chemotherapy (now frequently employed pre-hepatectomy for Colorectal liver metastases (CRLM)), HS and steatohepatitis. Furthermore, raised body mass index (BMI) predisposes to HS. However, no previous study has analysed the effect of HS on long-term survival.

Method: A retrospective analysis of a prospective consecutive cohort of 102 patients undergoing hepatectomy with 60 months follow-up data was performed. Resection specimens were examined histologically and the degree of steatosis graded accordingly. The data was compared to BMIs and other clinical characteristics. Statistical analyses included Log-Rank, Contingency, Logistic Regression and Fisher’s Exact Tests.

Results: No detectable fatty change in 27 patients; 1 patient had cirrhosis; 57 had HS: 26 graded mild; 10 moderate, 21 severe and 17 not graded. 1 patient (BMI 29.5 $\mathrm{kg} / \mathrm{m}^{2}$ ) had steatohepatitis but survived surgery. No significant difference in median survival between patients with and without HS (28.6 vs. 32.3 months, log rank p>0.05). Results were similar between patients with BMI $<25$ and BMI $\geq 25$ (32.3 vs. 36.8 months, $\log$ rank $\mathrm{p}>0.05$ ). Analyses of BMI against steatosis grade showed that patients with a higher BMI were at an increased risk of having a more severe HS (Logistic Regression, $\mathrm{p}<0.01$; Fisher's Exact, $\mathrm{P}<0.01$ ). Contingency analyses on the influence of diabetes, chemotherapy and increasing number of risk factors on the likelihood of obtaining HS were insignificant (Fisher's Exact, all p>0.05).

Conclusion: While patients with higher Body Mass Index values are at increased risk of having more severe hepatic steatosis, neither BMI nor hepatic steatosis significantly influences long-term survival. We conclude therefore that neither obesity nor hepatic steatosis has significant prognostic relevance on long-term survival of CRLM patients undergoing hepatectomy 


\section{$\underline{\text { Introduction }}$}

Hepatic steatosis is a histopathological state in which there is infiltration and excessive accumulation of lipids within hepatocytes ${ }^{(1)}$. The true incidence of hepatic steatosis remains unknown, however it has been reported that 34\% of adult Americans have hepatic steatosis as detected by magnetic resonance spectroscopy ${ }^{(2)}$, increasing to $93 \%$ in severely obese subjects in one recent case series study ${ }^{(3)}$.

The aetiology of hepatic steatosis is multi factorial and can be categorised into seven main categories (alcohol induced, primary, nutritional, metabolic, drug-induced, toxin induced and infectious) ${ }^{(4)}$. With the current prevalence of obesity in the UK increasing, it is expected that these figures will be comparable to those obtained in studies conducted in the USA and hence it remains the single most concerning aetiological factor for development of non-alcoholic fatty liver disease (NAFLD).

The pathophysiology of NAFLD disease remains uncertain; however the most supported theory postulates that insulin resistance is the key mechanism in the pathogenesis of NAFLD. Hepatic steatosis results if free fatty acid synthesis exceeds triglyceride exportation. This may occur via a variety of mechanisms but is most commonly seen due to insulin resistance and increased hepatocellular free fatty acid neosynthesis from acetate following increased alcohol exposure. ${ }^{(4-7)}$

Steatosis independently is considered reversible to some extent if the underlying aggravating factor is removed. However, if the steatosis is severe and accompanied by inflammation, it may develop into steatohepatitis. In 1998, Day CP et al ${ }^{(8)}$ proposed the "two-hit" model of steatohepatitis, whereby the "first-hit" involves the progression to hepatic steatosis via the insulin resistance mechanism. Once developed, the majority (70-75\%) will continue with steatosis, whilst $20-25 \%$ will progress to steatohepatitis- the "second-hit". These authors suggest that steatosed hepatocytes act as a reservoir of hepato-toxic agents and are subsequently more susceptible to oxidative stress caused by endotoxin, cytokines and environmental toxins- the "second-hit”. As our population is becoming increasingly obese, and liver resection plays an ever-more important role in the management of metastatic colorectal cancer, this problem is now of even greater clinical relevance. The initiation of various 
chemotherapy regimens for colorectal cancer may predispose to further oxidative stress causing progression of benign steatosis to steatohepatitis. Additionally, it is widely perceived that post-operatively fatty accumulation affects hepatocyte homeostasis and thus potentially impairs the recovery of steatotic livers, post liver resection (steatosis as RF in liver surg: ann surg 2007 aug). Hence, unsurprisingly it would appear logical that most clinicians would be hesitant to administer aggressive chemotherapy regimens in such patients for fear of intra-operative and post operative complications.

A recent report showed that the use of chemotherapy, and in particular Irinotecan, is associated with an increased risk of hepatic steatosis and steatohepatitis ${ }^{(9)}$. The authors concluded that steatohepatitis is associated with an increased mortality after hepatectomy and the use of Irinotecan should be carefully considered. Recent studies reported steatosis as an independent factor for morbidity and mortality rates in patients undergoing hepatectomy ${ }^{(10,11,12)}$. Considering the pathophysiology and risk factors for steatohepatitis, and in view of the evidence given above, it would appear that hepatic steatosis and obesity are relative contraindications in patients undergoing hepatectomy for CRLM. However, none of the studies above evaluated the effect of hepatic steatosis on the long-term survival of CRLM patients.

Therefore, the primary objective of this study is too evaluate the prognostic significance of hepatic steatosis, on a microscopic level, and increased body mass index (BMI) value in the long term survival of CRLM patients and to assess whether these patients should be offered surgery. 


\section{$\underline{\text { Methods }}$}

Clinical and follow-up data were retrieved retrospectively from a prospective consecutive cohort of 102 CRLM patients who underwent hepatectomy with intention-to-treat at Aintree University Hospital between April 2002 and October 2006. Data collected include patient demographics, survival data, relevant clinical characteristics (BMI values, alcohol consumption, medications, diabetes, triglyceride measurements and chemotherapy regimen) and operative details.

Two consultant pathologists with hepatobiliary expertise were blinded to the clinical data and independently determined the degree of hepatocellular steatosis in the resected specimens. The degree of steatosis was graded as defined by Kleiner et $a l^{25}$ (Figure- $4^{25,26}$ ): no fatty change $(<5 \%$ ), mild ( 5 to $<33 \%$ ), moderate (33 to $<66 \%$ ) or severe $(\geq 66 \%)$. Steatohepatitis and cirrhotic livers were also described. Steatosis data were then analysed against survival, Body Mass Index (BMI) and other relevant prognostic factors such as chemotherapy regimens.

Statistical analyses were performed using Fisher's exact test for nominal data, Logrank test for survival data and logistic regression when analysing ordinal data with continuous data. A p-value of $<0.05$ was considered to be statistically significant. Deaths within 30 days are excluded from all analyses. JMP version 6 (SAS Institute, Cary, NC, USA), Microsoft Excel (Microsoft Office 2007) were used to perform the various statistical functions 


\section{$\underline{\text { Results }}$}

\section{Patient demographics}

Table 1 summarises the demographics and clinical pathological characteristics of the 102 patients in this study. There were 40 women and 62 men with median survivals of 28.7 months (95\% CI 19.4-37.6) and 32.3 months (95\% CI 23.8-50.2) respectively. The median age of the population was 64.9 years (IQR 57.3-70.5 years).

\section{$\underline{\text { Clinicopathological Characteristics }}$}

In 16 patients the degree of steatosis was not graded, 1 was cirrhotic, 1 had steatohepatitis, 27 had no detectable fatty change, 57 were steatotic: 26 graded mild; 10 graded moderate; 21 graded severe. BMI value was irretrievable for 29 patients, 44 had normal BMI (<25 kg/m²), 29 had raised BMI $\left(>25 \mathrm{~kg} / \mathrm{m}^{2}\right)$ : 15 were overweight (BMI $\left.25-29.9 \mathrm{~kg} / \mathrm{m}^{2}\right), 10$ were obese $\left(30-24.9 \mathrm{~kg} / \mathrm{m}^{2}\right)$ and 4 were severely obese $(\geq 35$ $\left.\mathrm{kg} / \mathrm{m}^{2}\right)$.

Neoadjuvant chemotherapy was administered in 51 patients: 14 had Fluorouracil with Folinic Acid (5FU/FA), 15 had 5FU/FA with Oxaliplatin, 1 had 5FU/FA with Irinotecan, 1had 5FU/FA with Irinotecan and Oxaliplatin, 20 had unspecified chemotherapy.

\section{Correlation with Hepatic Steatosis}

Contingency analyses on the correlation between neoadjuvant chemotherapy and hepatic steatosis, diabetes mellitus and hepatic steatosis, BMI value and steatosis and the extent of hepatectomy (major hepatectomy defined as resection of $>3$ segments) and steatosis are shown in Figure 1. Statistically, adjuvant chemotherapy, diabetes and extent of hepatectomy are not significantly correlated to hepatic steatosis (Fisher's exact $\mathrm{P}>0.05$ ). However results showed that the presence of hepatic steatosis is more likely in patients with raised BMI $\left(>25 \mathrm{~kg} / \mathrm{m}^{2}\right)$, than in patients with normal BMI (Fisher's Exact Test $\mathrm{P}<0.01$ ). The significance is maintained when steatosis is further stratified by severity. It can be seen that the proportion of patients with raised BMI increases with increasing severity of steatosis (Pearson's Test and Likelihood Ratio, $\mathrm{P}<0.05$ ) (see Table 2). 
Figure 2 shows the Logistic Cumulative Probability Plot of BMI Value against steatosis grade. Here, the BMI value is plotted along the $\mathrm{x}$ axis and the probability of each steatosis grade on the y axis. Clearly, as the BMI value increases, the probability of a having a more severe degree of steatosis also increases (Whole model Tests $\mathrm{P}<0.001)$.

\section{$\underline{\text { Survival analyses }}$}

Subsequent analyses compared the difference in survival between patients stratified by BMI grades (Figure 3a), by the degree of hepatic steatosis (figure $3 b$ ) and by the extent of hepatectomy. Statistically there is no significant difference in survival between patients with different BMI grades, the degrees of hepatic steatosis or the extent of hepatectomy (Log Rank, p>0.05). Similar results were found on subgroup analyses where patients were stratified according to BMI cut-off value of $25 \mathrm{~kg} / \mathrm{m}^{2}$ (Log Rank, $\mathrm{P}>0.05$ ) and where patients were stratified according to the presence of hepatic steatosis (Log Rank, $\mathrm{P}>0.05$ ). Moreover, survival analysis on the patients who had major hepatectomy stratified by the steatosis status yield insignificant results (Log Rank P>0.05) (see Table 3).

In Summary, neither hepatic steatosis nor BMI values significantly influences the long term survival of patients with CRLM who underwent hepatectomy. 


\section{Discussion}

The effect of hepatic steatosis on short term post operative outcomes has been widely investigated ${ }^{(9-13)}$. The general underlying theme in these studies seemed to indicate that patients with steatosis were susceptible to a more arduous post operative course with respect to complication rates and short term morbidity. It was postulated that steatosis may have interfered with post operative hepatic regeneration and hence would result in an adverse outcome for patients undergoing partial hepatectomy. Resultantly, this has led to concerns that moderate to severe steatosis are relative contraindications to hepatectomy, and that surgeons should avoid the temptation to resect aggressively in this scenario.

Recent studies have challenged the theory that obese patients predispose to post operative complications or mortality ${ }^{(14)}$. Counter to these observations, there is only one study in the literature that reported that steatosis did not affect 60 day mortality rates ${ }^{(15)}$.

To our knowledge, our study is the first to analyse the long-term relationship between hepatic steatosis, raised BMI and survival of patients with CRLM undergoing hepatectomy. Whilst we report that patients with higher BMI values are at increased risk of developing more severe hepatic steatosis, it must be noted that neither BMI nor hepatic steatosis is an independent prognostic factor of long-term survival after resection of CRLM.

This observation could imply that hepatic steatosis does not correlate with impaired hepatic regeneration. This view is shared by others who examined hepatic regeneration following hepatectomy, and found that though alcoholic steatohepatitis and NAFLD shared similar hepatic histology, liver regeneration was not impaired in NAFLD ${ }^{(16)}$.

Secondary analyses compared the distribution of hepatic steatosis amongst patients with a positive history of diabetes mellitus or chemotherapy. Results from both analyses suggest that statistically, the likelihood of steatosis in patients with DM or patients who had chemotherapy is insignificantly different to those without. It is also 
reported that increasing number of risk factors in a patient does not have a significant bearing on the risk of developing hepatic steatosis. This is most likely due to the multifactorial nature of the pathogenesis in hepatic steatosis and suggests that each singular factor does not have a synergistic effect when combined with another factor. This is somewhat surprising as one would expect patients with DM to demonstrate increased levels of steatosis secondary to them having the metabolic syndrome. Of more clinical relevance though is the fact that pre-operative chemotherapy did not appear to impinge upon development of steatosis, at the levels used.

Perhaps the most interesting finding in this study is that for a given BMI value, the Logistic Cumulative Probability Plot may be used to estimate the likelihood of the degree of hepatic steatosis in a patient. This is particularly important because although our study reports that hepatic steatosis does not influence the long-term post-operative mortality, there is no doubt that steatosis and obesity are associated with increased postoperative morbidity. The development and improvement of such a model may improve the post-operative management plan for such patients 


\section{Conclusion}

In light of the results already discussed, we conclude that the long-term survival of patients with colorectal liver metastases undergoing curative hepatic surgery is not influenced by their Body Mass Index value or the degree of hepatic steatosis. Subsequently therefore, they are not contraindicated for hepatic surgery.

Furthermore, a clinical history of diabetes or chemotherapy treatment does not independently predict the presence of hepatic steatosis. In addition, the presence of an increasing number of risk factors does not have significant bearings on the likelihood or degree of hepatic steatosis.

\section{Conflict of interest}

The authors state that they have no conflict of interest. 


\section{Reference:}

1. Chiappini F, Barrier A, Saffroy R, Domart R, Dagues N, Azoulay D, Sebagh 5 et al. Exploration of global gene expression in human liver steatosis by highdensity oligonucleotide microarray. Lab Invest. 2006;86(2):154-65

2. Browning JD, Szczepaniak L, Dobbins R, Nuremberg P, Horton JD, Cohen JC et al. Prevalence of Hepatic Steatosis in an Urban Population in the United States: Impact of Ethnicity. Hepatol. 2004;40:1387-1395

3. Ong JP, Elariny H, Collantes R, Younoszai A, Chandhoke V, Reines HD et al Predictors of non-alcoholic steatohepatitis and advanced fibrosis in morbidly obese patients. Obes Surg. 2005;15:310-315

4. Angulo P. Obesity and Nonalcoholic Fatty Liver Disease. Nutr Rev. 2007;65(6):S57-S63

5. Cotran RS, Kumar V, Collins T. Robbins Pathologic Basis of Disease, $6^{\text {th }}$ ed. Philadelphia: Saunders, 1999: 39-40

6. McCullough JA. Pathophysiology of Nonalcoholic Steatohepatitis. J Clin Gastroenterol. 2006;40(1):S17-S29

7. Yan E, Durazo F, Tong M, Hong K. Nonalcoholic Fatty Liver Disease: Pathogenesis, Identification, Progression, and Management. Nutr Rev. 2007; 65(8):376-84

8. Day CO, James OF. Steatohepatitis: a tale of two "hits"? Gastroenterol. 1998;114:842-845

9. Vauthey JN, Pawlik TM, Ribero D, Wu TT, Zorzi D, Hoff PM et al. Chemotherapy Regimen Predicts Steatohepatitis and an Increase in 90-Day Mortality After Surgery for Hepatic Colorectal Metastases. J Clin Oncol. 2006;24(13):2065-2072

10. Vetelainen R, van Vliet A, Gouma DJ, Gulik TM. Steatosis as a risk factor in liver surgery. Ann Surg. 2007;245:20-30

11. McCormack L, Petrowsky H, Jochum W, Furrer K, Clavien PA. Hepatic steatosis is a risk factor for postoperative complications after major hepatectomy. Ann Surg. 2007;245:923-930

12. Gomez D, Malik HZ, Bonny GK, Wong V, Toogood GJ, Lodge JPA et al. Steatosis predicts postoperative morbidity following hepatic resection 
13. McCormack L, Capitanich $P$ et al. Liver surgery in presence of cirrhosis or steatosis: Is morbidity increased? Patient Saf Surg.2008 Apr 25;2:8

14. Mullen JT, Davenport DL, Hutter MM. Impact of body mass index on perioperative outcomes in patients undergoing major intra-abdominal cancer surgery. Ann Surg Oncol. 2008 Aug;15(8):2164-72. Epub 2008 Jun 12

15. Zhang BH, Weltman M, Farrell GC. Does steatohepatitis impair liver regeneration? A study in a dietary model of non-alcoholic steatohepatitis in rats. J Gastroenterol Hepatol. 1999 Feb;14(2):133-7.

16. Kooby DA, Blumgart LH et al. Impact of Steatosis on peri-operative outcome following hepatic resection. J Gastrointest Surg 2003 Dec;7(8):1034-44 


\begin{tabular}{|c|c|c|c|}
\hline Variable & $\begin{array}{c}\text { Female } \\
(n)\end{array}$ & Male (n) & $\begin{array}{c}\text { Combined } \\
(n)\end{array}$ \\
\hline No. of Patients & 40 & $\overline{62}$ & 102 \\
\hline $\begin{array}{l}\text { Median } \\
\text { Inter Quartile Range }\end{array}$ & $\begin{array}{l}67 \text { yrs } \\
57-73 \text { yrs }\end{array}$ & $\begin{array}{l}63 \text { yrs } \\
58-70 y r s\end{array}$ & $\begin{array}{l}65 \text { yrs } \\
57-71 \text { yrs }\end{array}$ \\
\hline Major (>50\%) Resection & 17 & 37 & 54 \\
\hline $\begin{array}{l}\text { Body Mass Index } \\
\text { Median }\end{array}$ & & & $24.9 \mathrm{~kg} / \mathrm{m}^{2}$ \\
\hline Acceptable $\left(<25 \mathrm{~kg} / \mathrm{m}^{2}\right)$ & 20 & 24 & 44 \\
\hline $\begin{array}{l}\text { Overweight }(25-29.9 \\
\left.\mathrm{kg} / \mathrm{m}^{2}\right)\end{array}$ & 8 & 7 & 15 \\
\hline Obese $\left(30-34.9 \mathrm{~kg} / \mathrm{m}^{2}\right)$ & 0 & 10 & 10 \\
\hline $\begin{array}{l}\text { Severely Obese }(\geq 35 \\
\left.\mathrm{kg} / \mathrm{m}^{2}\right) \\
\text { Degree of Steatosis }\end{array}$ & 2 & 2 & 4 \\
\hline Indeterminate & 7 & 9 & 17 \\
\hline $\begin{array}{l}\text { Cirrhosis, no fatty } \\
\text { change }\end{array}$ & & & 1 \\
\hline Steatohepatitis & 1 & 0 & 1 \\
\hline $\begin{array}{l}\text { No Fatty Change } \\
\text { Mild }\end{array}$ & $\begin{array}{c}10 \\
8\end{array}$ & $\begin{array}{l}17 \\
18\end{array}$ & $\begin{array}{l}27 \\
26\end{array}$ \\
\hline Moderate & 4 & $\begin{array}{c}10 \\
6\end{array}$ & 10 \\
\hline $\begin{array}{l}\text { Severe } \\
\text { Survival }\end{array}$ & 10 & 11 & 21 \\
\hline Median Survival & $\begin{array}{c}28.7 \\
\text { Months }\end{array}$ & $\begin{array}{l}32.3 \\
\text { Months }\end{array}$ & $\begin{array}{l}30.2 \\
\text { Months }\end{array}$ \\
\hline $\begin{array}{l}\text { Neoadjuvant Chemotherapy } \\
(n=79)\end{array}$ & 31 & 48 & 79 \\
\hline Irretrievable data & 9 & 14 & 23 \\
\hline Yes & 19 & 32 & 51 \\
\hline No & 14 & 14 & 28 \\
\hline 5FU/FA & 5 & 9 & 14 \\
\hline 5FU/FA + 0xaliplatin & 4 & 11 & 15 \\
\hline $\begin{array}{l}\text { 5FU/FA + Oxaliplatin + } \\
\text { Irinotecan }\end{array}$ & $\boldsymbol{0}$ & 1 & 1 \\
\hline 5FU/FA + Irinotecan & 1 & 0 & 1 \\
\hline Unspecified Chemotherapy & 7 & 13 & 20 \\
\hline History of Diabetes Mellitus & 4 & 6 & 10 \\
\hline Statin treatment & 10 & 7 & 17 \\
\hline
\end{tabular}




\begin{tabular}{|c|c|c|c|c|}
\hline Clinical Characteristic & $\overline{\mathrm{n}}$ & Statistical Test & $\overline{\mathrm{R}^{2}}$ & p-value \\
\hline BMI (continuous) & 61 & Whole Model Test & 0.089 & 0.0001 \\
\hline $\begin{array}{l}\text { BMI } \\
\left(<25 \mathrm{Vs} \geq 25 \mathrm{~kg} / \mathrm{m}^{2}\right)\end{array}$ & $\begin{array}{l}61 \\
61 \\
61\end{array}$ & $\begin{array}{c}\text { Fisher's Exact } \\
\text { Likelihood Ratio } \\
\text { Pearson }\end{array}$ & $\begin{array}{l}0.088 \\
0.115 \\
0.115\end{array}$ & $\begin{array}{c}<0.001 \\
0.026 \\
0.032\end{array}$ \\
\hline Diabetes Mellitus & 69 & Fisher's Exact & 0.002 & N.S. \\
\hline Chemotherapy & 66 & Fisher's Exact & 0.002 & N.S. \\
\hline Hepatectomy (major Vs Minor) & 79 & Fisher's Exact & 0.002 & N.S. \\
\hline n.s. not significant $\mathrm{p}>0.05$ & & & & \\
\hline
\end{tabular}

\begin{tabular}{|c|c|c|c|c|c|}
\hline \multicolumn{5}{|c|}{ Table 3- Summary of Survival Analyses } & \multirow{3}{*}{$\begin{array}{c}\begin{array}{c}\mathrm{L} 0 \mathrm{~g}-\mathrm{R} \text { a } \mathrm{n} k \\
\text { p-value }\end{array} \\
\end{array}$} \\
\hline \multirow{2}{*}{ Parameter } & \multirow{2}{*}{$\mathrm{n}$} & \multirow{2}{*}{$\begin{array}{c}\text { Media n } \mathrm{S} \text { urvival } \\
\text { (months) }\end{array}$} & \multicolumn{2}{|c|}{$95 \% \mathrm{CI}$} & \\
\hline & & & Lower & Upper & \\
\hline \multicolumn{6}{|l|}{ BMI (n=73) } \\
\hline$<25 \mathrm{~kg} / \mathrm{m}^{2}$ & 44 & 32.3 & 19.5 & 50.2 & \multirow{2}{*}{ N.S. } \\
\hline$\geq 25 \mathrm{~kg} / \mathrm{m}^{2}$ & 29 & 36.8 & 23.8 & 66.6 & \\
\hline \multicolumn{6}{|l|}{ BMI Graded $(n=73)$} \\
\hline Acceptable & 44 & 32.3 & 19.5 & 50.2 & \multirow{4}{*}{ N.S. } \\
\hline Overweight & 15 & 41.5 & 16.1 & 66.6 & \\
\hline Obese & 10 & 27.2 & 12.5 & NR & \\
\hline Severely Obese & 4 & N/A & 11.7 & NR & \\
\hline \multicolumn{6}{|l|}{ Steatosis $(\mathrm{n}=84)$} \\
\hline No Steatosis & 27 & 32.3 & 22.6 & 62.0 & \multirow{2}{*}{ N.S. } \\
\hline Steatosis & 57 & 28.6 & 21.7 & 41.5 & \\
\hline \multicolumn{6}{|l|}{ Steatosis Graded $(\mathrm{n}=84)$} \\
\hline No fatty change & 27 & 32.3 & 22.6 & 62.0 & \multirow{4}{*}{ N.S. } \\
\hline Mild & 26 & 37.5 & 21.1 & NR & \\
\hline Moderate & 10 & 23.3 & 8.2 & NR & \\
\hline Severe & 21 & 28.6 & 15.6 & 41.5 & \\
\hline \multicolumn{6}{|l|}{ Hepatectomy $(\mathrm{n}=96)$} \\
\hline Major hepatectomy & 61 & 29.8 & 23.3 & 42.4 & \multirow[t]{2}{*}{ N.S. } \\
\hline Minor hepatectomy & 35 & 30.3 & 19.4 & 56.8 & \\
\hline \multicolumn{6}{|c|}{ Major Hepatectomy $(n=49)$} \\
\hline No Steatosis & 17 & 45.6 & 17.1 & 62.1 & \multirow{2}{*}{ N.S. } \\
\hline Steatosis & 32 & 27.2 & 19.5 & 37.5 & \\
\hline
\end{tabular}




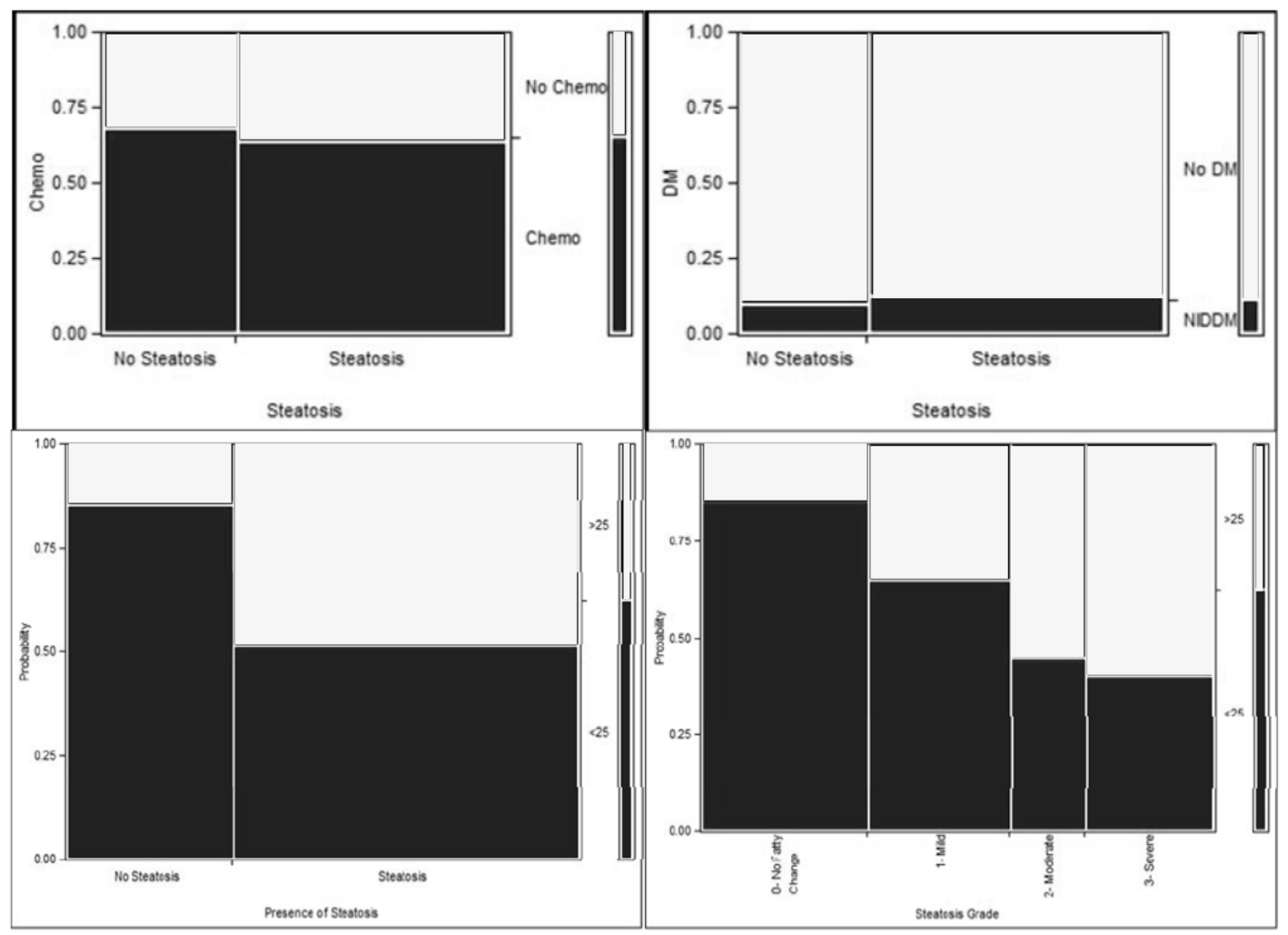

Figure 1- Contingency Analyses of neoadjuvant chemotherapy, DM and BMI against steatosis

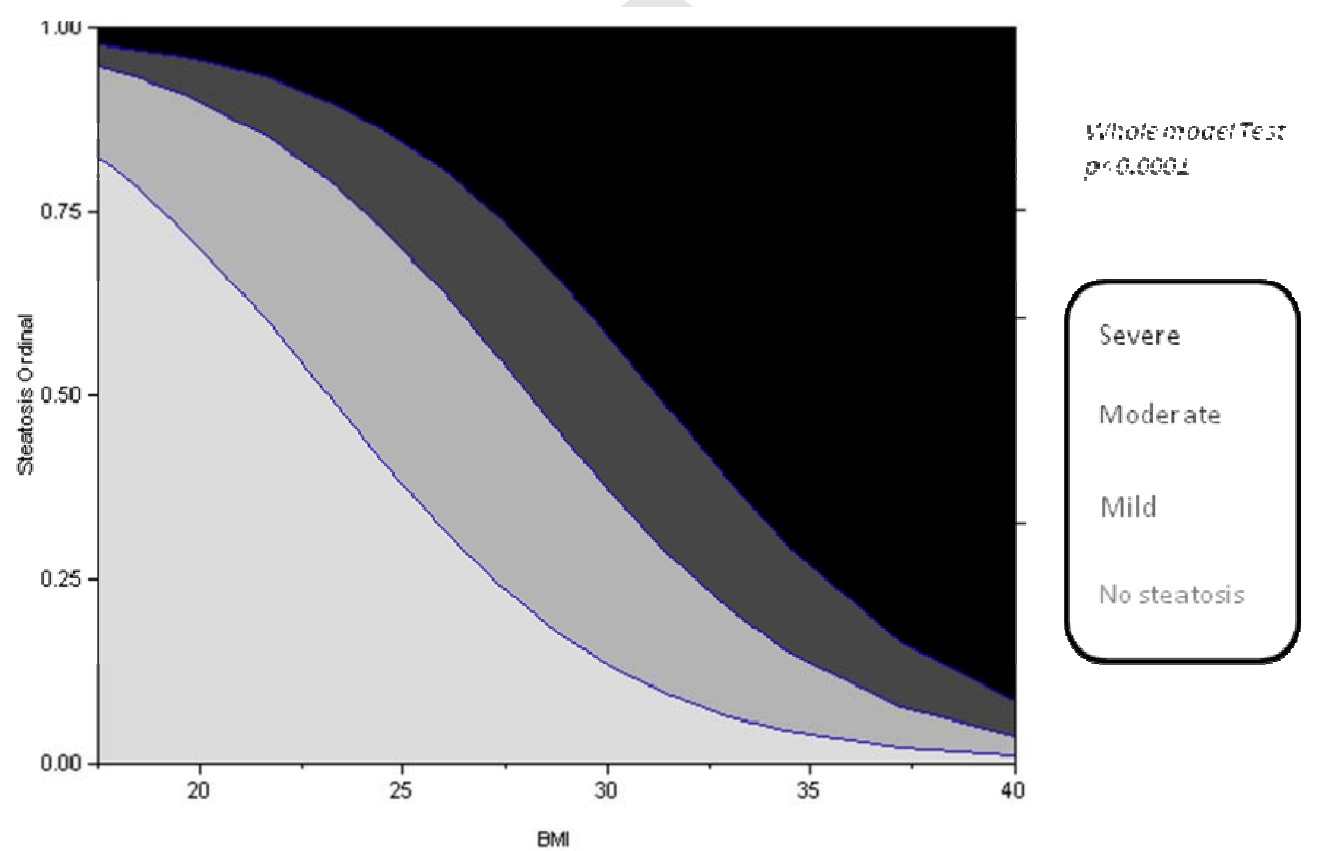

Figure 2- Logistic Cumulative Probability Plot of BMI value against steatosis grades 


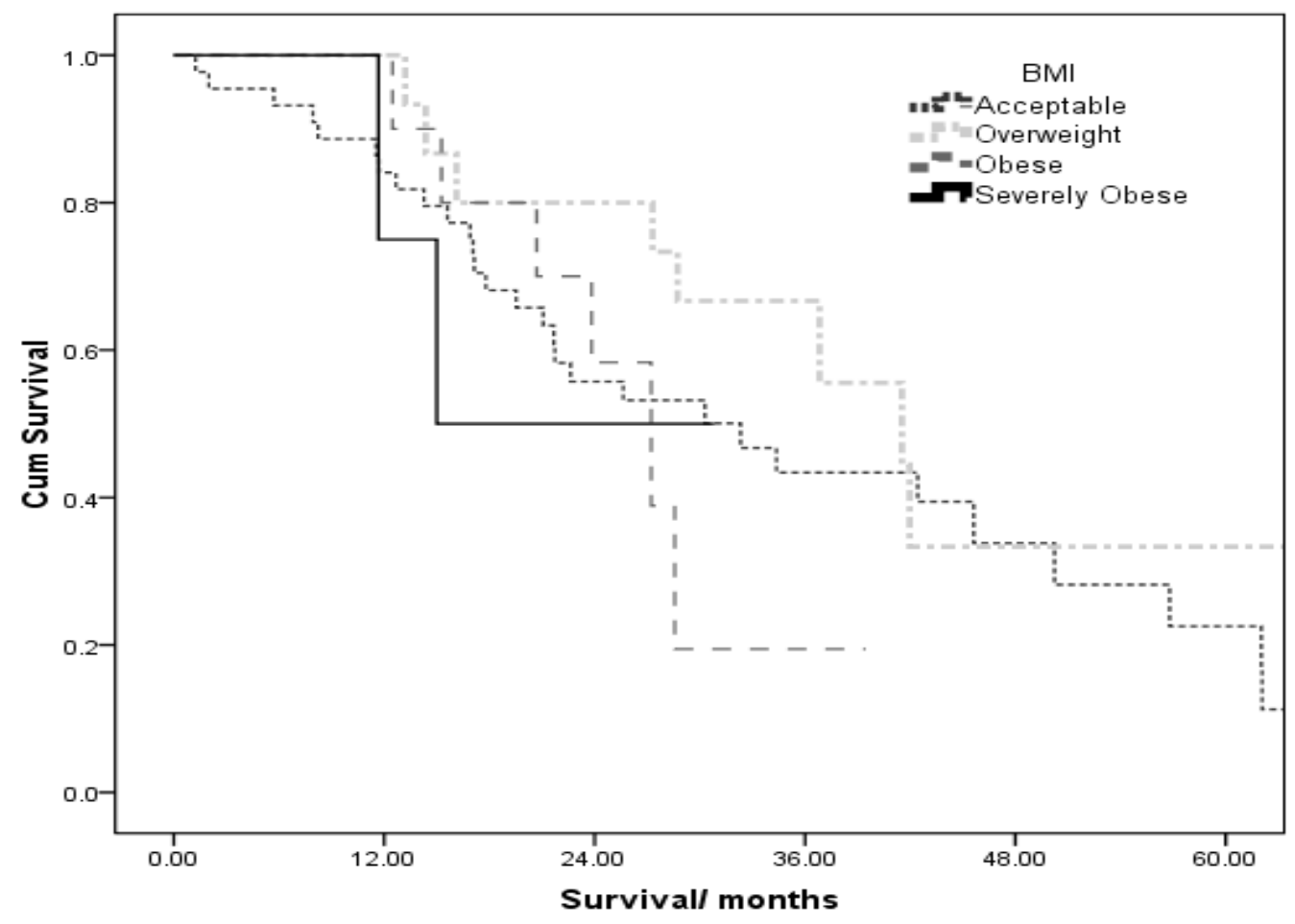

Figure 3a- Kaplan-Meier Survival Curve for BMI grades

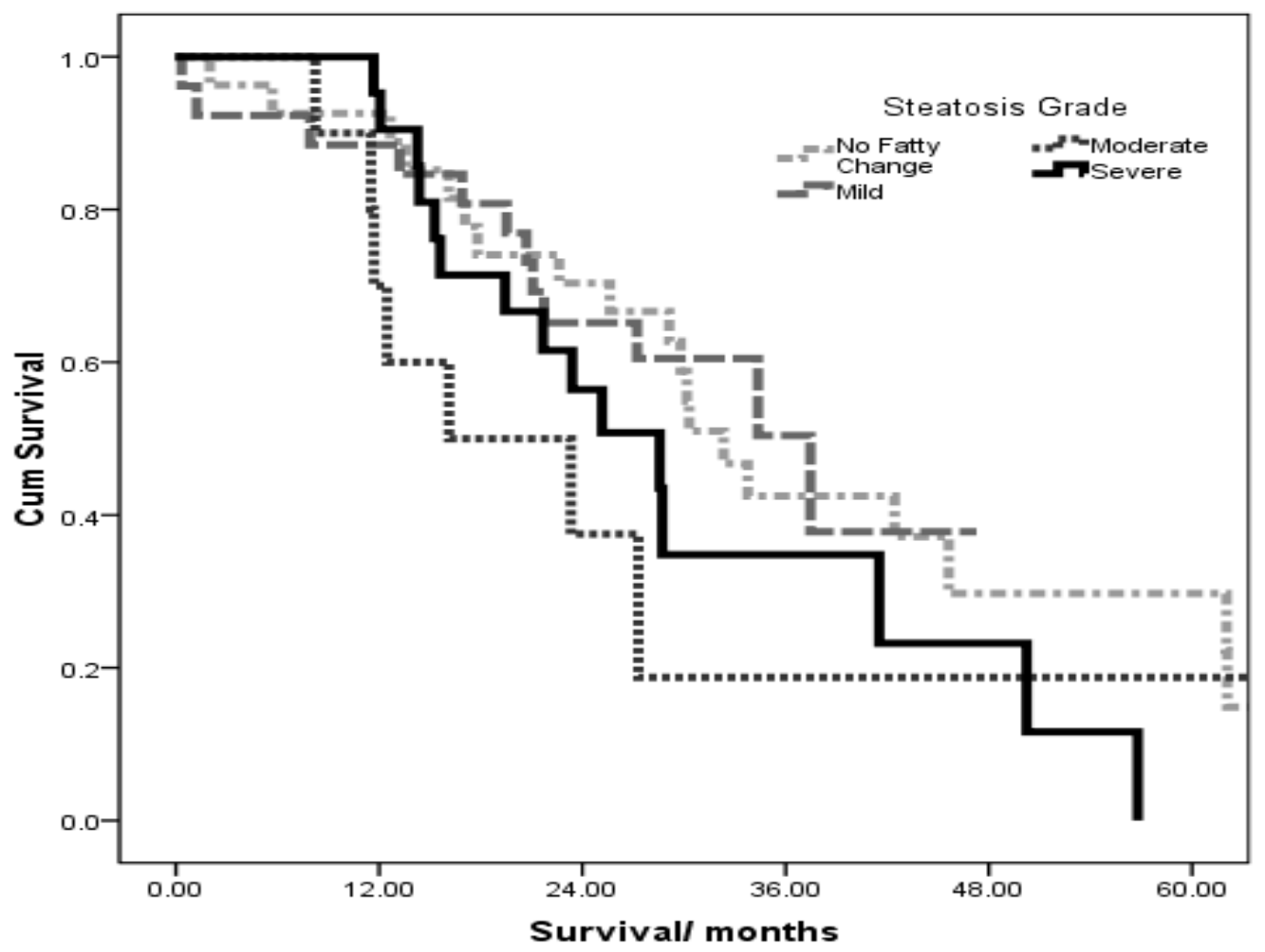

Figure 3b-Kaplan-Meier Survival Curve for steatosis grades 